\title{
The long-term impact of various techniques for tricuspid repair in Ebstein's anomaly
}

\author{
Roland Hetzer, MD, PhD, ${ }^{a}$ Paul Hacke, ${ }^{\mathrm{b}}$ Mariano Javier, ${ }^{\mathrm{a}}$ Oliver Miera, MD, ${ }^{\mathrm{b}}$ \\ Katharina Schmitt, MD, PhD, ${ }^{\mathrm{b}}$ Yuguo Weng, $\mathrm{MD}, \mathrm{PhD},{ }^{\mathrm{a}}$ and Eva Maria Delmo Walter, $\mathrm{MD}, \mathrm{PhD}^{\mathrm{a}}$
}

\begin{abstract}
Objective: We describe a repertoire of repair techniques according to type of Ebstein's anomaly to correct tricuspid valve (TV) incompetence, and report long-term ventricular function and functional outcomes.

Methods: Sixty-eight patients (mean age, $26.9 \pm 7.3$ years) with Ebstein's anomaly (type $A, n=21$; type $B, n=23$; type $C, n=15$; type $D, n=9$ ) underwent correction of TV incompetence under normothermic cardiopulmonary bypass. The atrialized ventricle, TV, and subvalvar apparatus were inspected to analyze the precise morphology and determine which leaflet was the most mobile. Various repair strategies (anterior and/or posterior annulorrhapy, Sebening stitich, doubleorifice valve technique, with bidirectional Glenn anastomosis if necessary) were used according to the presenting morphology and applied according to the type of Ebstein's anomaly. In all, the atrialized right ventricle (RV) was incorporated into the contractile RV by partial closure of the natural annulus using the most mobile leaflet for valve competence.
\end{abstract}

Results: The mean duration of follow-up was $13.25 \pm 1.3$ years (median, 9.34 years; range, 1-24 years). The mean New York Heart Association class improved from 3.4 to $1.3(P<.001)$. The mean severity of TV incompetence was reduced from 3.2 to $1.3(P<.001)$. Exercise tolerance tests demonstrated improved maximal oxygen uptake from a mean of $15 \pm 7.8 \mathrm{ng} / \mathrm{kg} / \mathrm{min}$ preoperatively to a mean of $24.9 \pm 2.0 \mathrm{ng} / \mathrm{kg} / \mathrm{min}$ postoperatively $(P<.02)$. Displacement tissue Doppler imaging was used to evaluate overall cardiac performance of the $\mathrm{RV}$ and left ventricle and interventricular septum. The mean basal, middle, and apical ventricular strain improved significantly from preoperative values of $18.08 \%, 15.6 \%$, and $13.9 \%$, respectively to postoperative values of $25.7 \%$ $(P<.011), 23.7 \%(P<.001)$, and $19.36 \%(P<.05)$, respectively. Freedom from reoperation was $100 \%$ at 1 year, $98.3 \%$ at 5 years, and $92.9 \%$ at 20 years. Early mortality was $2.9 \%$, and late mortality was $5.8 \%$. The overall survival rate was $97.6 \%$ at 30 days, $92.7 \%$ at 5 years, and $91.26 \%$ at 20 years.

Conclusions: The various repair techniques, all of which preserve the atrialized chamber and are used individually according to morphology, provide satisfactory long-term ventricular function and functional outcome even in severe types of Ebstein's anomaly. (J Thorac Cardiovasc Surg 2015;150:1212-9)

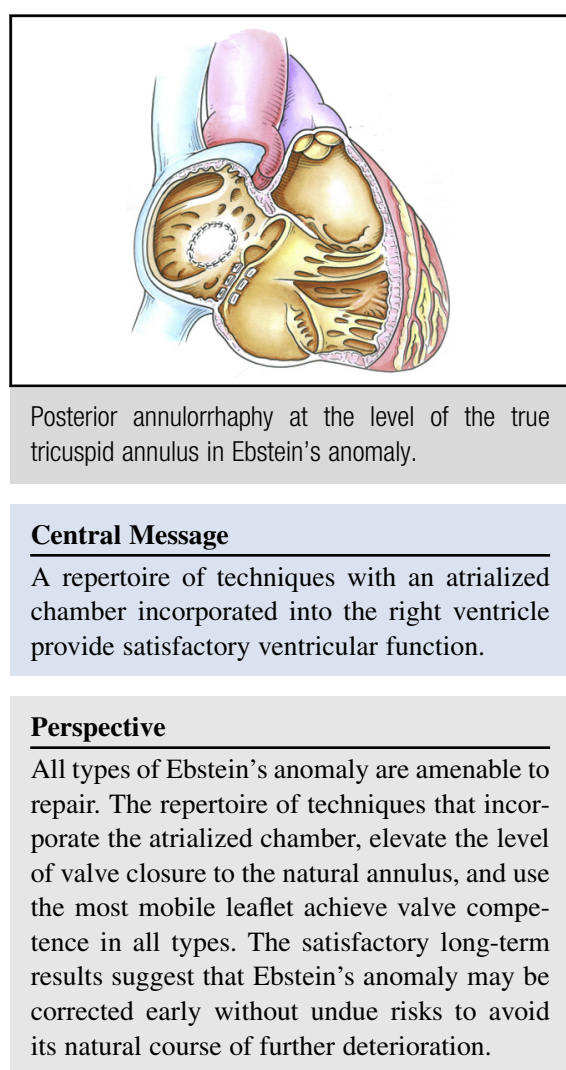

See Editorial Commentary page 1220.
From the Departments of a Cardiothoracic and Vascular Surgery and ${ }^{\mathrm{b}}$ Congenital Heart Disease/Pediatric Cardiology, Deutsches Herzzentrum Berlin, Berlin, Germany.

Read at The American Association for Thoracic Surgery Mitral Conclave, New York, NY, May 2-3, 2013.

Received for publication April 29, 2013; revisions received Aug 3, 2015; accepted for publication Aug 11, 2015; available ahead of print Sept 5, 2015.

Address for reprints: Eva Maria Delmo Walter, MD, PhD, Deutsches Herzzentrum Berlin, Augustenburger Platz 1, 13353 Berlin, Germany (E-mail: eva.delmowalter@ gmail.com).

0022-5223/\$36.00

Copyright (c) 2015 by The American Association for Thoracic Surgery

http://dx.doi.org/10.1016/j.jtcvs.2015.08.036
Ebstein's anomaly ${ }^{1}$ is a congenital defect of the tricuspid valve (TV), in which the origins of the variably deformed septal or posterior leaflets, or both, are displaced downward into the right ventricle (RV), dividing it into a proximal atrialized and distal ventricularized (true or functional ventricle) chambers. ${ }^{2}$ These features, in addition to annular dilatation, result in varying degrees of valve incompetence, which exacerbates the abnormalities in structure and function of the $\mathrm{RV}^{3}$ and less commonly, those of the left ventricle (LV). ${ }^{4}$ Pulmonary hypoplasia, ${ }^{5}$ a feature that 


$$
\begin{aligned}
& \text { Abbreviations and Acronyms } \\
& \begin{array}{ll}
\text { ET } & =\text { Ventricular ejection } \\
\text { FEV } & =\text { Forced expiratory volume } \\
\text { FVC } & =\text { Forced vital capacity } \\
\text { IVCT } & =\text { Isovolumetric contraction } \\
\text { IVRT } & =\text { Isovolumetric relaxation } \\
\text { IVS } & =\text { Interventricular septum } \\
\text { LV } & =\text { Left ventricle/ventricular } \\
\text { NYHA } & =\text { New York Heart Association } \\
\text { RV } & =\text { Right ventricle/ventricular } \\
\text { TDI } & =\text { Tissue Doppler imaging } \\
\text { TV } & =\text { Tricuspid valve } \\
\mathrm{VO}_{2 \max } & =\text { Maximal oxygen consumption }
\end{array}
\end{aligned}
$$

contributes to neonatal death as well as rhythm disturbances, ${ }^{6}$ are correlated with the degree of resultant tricuspid regurgitation. If left untreated, heart failure may eventually occur. $^{7}$ Thus, numerous techniques,${ }^{8-19}$ both anatomical and functional, have evolved in an attempt to correct the TV incompetence in Ebstein's anomaly and offset the symptoms. Most of these techniques are based on the plication of the tricuspid annulus associated or not associated with plication of the atrialized chamber. Despite reported good mid-term and long-term results of these techniques, the incidence of residual or recurrent TV insufficiency increases and the need for reoperation persists for many patients. Presently, no report exists defining which techniques are suitable for each type of Ebstein's anomaly.

Here we describe a repertoire of repair techniques according to type of Ebstein's anomaly to correct the TV incompetence, and report the long-term ventricular function and functional outcomes in patients undergoing these operations.

\section{PATIENTS AND METHODS}

Our hospital's Institutional Review Board approved this retrospective/ prospective study and waived the need for patient consent. Between June 1986 and December 2012, 68 patients (mean age, $26.9 \pm 7.3$ years) with Ebstein's anomaly underwent correction of TV incompetence (Table 1). The TV anatomy was categorized according to Carpentier's classification scheme $^{12}$ as type A, B, C, or D:

(1) Type A: a small, contractile atrialized chamber with a large, mobile anterior leaflet and the septal and posterior leaflet origins only moderately displaced into the $\mathrm{RV} ; \mathrm{n}=21$ (mean age, $22.89 \pm 18.86$ years; median, 18.07 years; range, 9 months to 64.8 years)

(2) Type B: large, noncontractile atrialized chamber with a large and mobile anterior leaflet; $\mathrm{n}=23$ (mean age, $32.04 \pm 17.2$ years; median, 33.49 years; range, $9.03-59.29$ years)

(3) Type C: restricted motion of anterior leaflet, which adheres to the endocardium of the RV wall by fibrous bands or abnormal chordae tendinae; $\mathrm{n}=15$ (mean age, $32.84 \pm 22.71$ years; median, 38.57 years; range, 7.9 months to 67.45 years)
(4) Type D: "tricuspid sac" leaflet tissue forming a continuous sac adherent to a dilated $\mathrm{RV} ; \mathrm{n}=9$ (mean age, $22.98 \pm 19.43$ years; median, 17.46 years; range, 2.8 months to 48.03 years).

Cyanosis, defined by a resting systemic oxygen saturation $<92 \%$ (range, 76\%-92\%), was present in 33 patients (48.5\%). Rhythm disturbances were exhibited by 25 patients $(36.7 \%)$. Cardiomegaly (cardiothoracic ratio $>65 \%$ ) was found in 51 patients $(75 \%)$. All patients age 10 years and older $(n=38)$ were subjected to exercise tolerance tests using the Jones protocol ${ }^{20}$ both perioperatively and during regular follow-ups. RV and LV function was evaluated in 19 patients based on standard Doppler echocardiography; since 2000, tissue Doppler imaging (TDI) has been used in all patients, including the surviving 13 patients from the early years, for perioperative and follow-up assessment of ventricular function and myocardial performance.

\section{Functional Evaluation}

We used the Jones protocol ${ }^{20}$ for exercise tolerance testing. This is a symptom-limited exercise test with a stepwise increase in workload of $16 \mathrm{~W} / \mathrm{min}$, starting with unloaded cycling plus the ergometer-related permanent load. Cuff blood pressure measurements and complete 12-lead electrocardiography readings were obtained at 2- to 3-minute intervals during exercise, at peak exercise, and at 1, 3, and 5 minutes after exercise. Expiratory gas analysis was performed using the $\mathrm{CardiO}_{2}$ (MCG Diagnostics, St. Paul, Minn) exercise testing system. Maximal oxygen consumption $\left(\mathrm{VO}_{2 \max }\right)$ was defined as the highest $\mathrm{VO}_{2}$ value detected during the test. Pulse oximetry oxygen saturation was monitored throughout the study. Immediately before each exercise test, spirometric measurements of the patient's forced vital capacity (FVC) and volume of air exhaled in the first second of forced expiration $\left(\mathrm{FEV}_{1}\right)$ were also obtained. The time-related change in $\mathrm{VO}_{2 \max }$ was the primary functional outcome for this study.

\section{Echocardiography and TDI}

Transthoracic echocardiography was performed with the patient in a left lateral recumbent position, using a transducer individually optimized to body weight (5.0-2.5 MHz) and interfaced with a Vivimed 7 system (GE Healthcare VingMed, Horten, Norway). For each parameter, at least 3 consecutive cardiac cycles were recorded during the respiratory idle state, stored in digital format (Magneto Optical Disc; Sony, Tokyo, Japan), and transferred to a computer workstation for offline analysis with a dedicated software (EchoPac; GE Healthcare). TDI was used to evaluate annular velocity and myocardial strain. Longitudinal performance was evaluated in a standard apical 4-chamber view. Radial function was assessed in a parasternal short-axis view at the LV posterior wall. ${ }^{21}$ Two-dimensional and color-sector sizes were minimized, and depth was chosen to achieve the highest frame rate (150-350 frames/second). The angle between myocardial motion and the ultrasound beam was kept at $<30^{\circ}$; therefore, each wall-even each segment of interest, if necessary-was recorded separately to obtain an optimal parallel angulation. Gain settings, filters, and pulse repetition frequency (0.16-0.28 per second) were adjusted to optimize color saturation and to avoid aliasing. Peak mean annular velocity profiles were derived at the level of the mitral valve annulus at the interventricular septum (IVS) and LV. Isovolumetric acceleration was derived at the left lateral wall. Isovolumetric contraction (IVCT) and isovolumetric relaxation (IVRT), as well as ventricular ejection (ET) times, were measured in a curved m-mode at the IVS. The Tei index was calculated as TDI-Tei $=($ IVCT + IVRT $) / E T .^{22}$ The longitudinal strain of the LV lateral wall and IVS were examined at their basal, middle, and apical segments, and the mean LV and IVS strain was calculated. Radial LV strain was examined at the LV posterior wall at the level of the papillary muscles in a parasternal short-axis view. A pixel resolution of $6 \times 8$ was applied, along with a computation distance of $9.7 \mathrm{~mm}$ in the longitudinal direction, for a radial strain of $4.7 \mathrm{~mm}$. The angle of the region of interest was adjusted to be parallel to the major direction of myocardial motion. 
TABLE 1. Characteristics of the 68 patients with Ebstein's anomaly

\begin{tabular}{|c|c|c|c|}
\hline Characteristic & \multicolumn{2}{|c|}{ Value } & $P$ value \\
\hline Age, mean (median; range) & \multicolumn{2}{|c|}{$27.8 \pm 19.7$ y $(20.86 ; 2.8$ mo to 67.4 y) } & \\
\hline Sex, female/male, $\mathrm{n}$ & \multicolumn{2}{|c|}{$45 / 23$} & \\
\hline \multicolumn{4}{|l|}{ Classification of Ebstein's anomaly } \\
\hline $\mathrm{A}, \mathrm{n}(\%)$ & \multicolumn{2}{|c|}{$21(30.9)$} & \\
\hline Age, mean (median; range) & \multicolumn{2}{|c|}{$22.89 \pm 18.86$ y $(18.07 \mathrm{y} ; 9$ mo to $64.8 \mathrm{y})$} & \\
\hline $\mathrm{B}, \mathrm{n}(\%)$ & \multicolumn{2}{|c|}{$23(33.8)$} & \\
\hline Age, mean (median; range) & \multicolumn{2}{|c|}{$32.04 \pm 17.2$ у (33.49 у; 9.03-59.29 y) } & \\
\hline $\mathrm{C}, \mathrm{n}(\%)$ & \multicolumn{2}{|c|}{$15(22.0)$} & \\
\hline Age, mean (median; range) & \multicolumn{2}{|c|}{$32.04 \pm 17.2$ у (33.49 y; 9.03-59.29 y) } & \\
\hline $\mathrm{D}, \mathrm{n}(\%)$ & \multicolumn{2}{|c|}{$9(23.6)$} & \\
\hline Age, mean (median; range) & \multicolumn{2}{|c|}{$22.98 \pm 19.43$ у $(17.46$ y; 2.8 mo-48.03 y) } & \\
\hline \multicolumn{4}{|l|}{ Clinical signs and symptoms, $\mathrm{n}(\%)$} \\
\hline Cyanosis & \multicolumn{2}{|c|}{$33(48.5)$} & \\
\hline Rhythm disturbances & \multicolumn{2}{|c|}{$25(36.8)$} & \\
\hline Cardiomegaly & \multicolumn{2}{|c|}{$51(75)$} & \\
\hline \multicolumn{4}{|l|}{ Associated anomalies, $\mathrm{n}(\%)$} \\
\hline Atrial septal defect & \multicolumn{2}{|c|}{$52(76.4)$} & \\
\hline Ventricular septal defect & \multicolumn{2}{|c|}{$4(5.9)$} & \\
\hline Pulmonary valve stenosis & \multicolumn{2}{|c|}{$7(10.2)$} & \\
\hline Partial anomalous pulmonary venous return & \multicolumn{2}{|c|}{$1(1.4)$} & \\
\hline Chiari network malformation & \multicolumn{2}{|c|}{$1(1.4)$} & \\
\hline \multirow{2}{*}{ Mitral valve insufficiency } & \multicolumn{2}{|c|}{$3(4.4)$} & \\
\hline & Preoperative & Postoperative & \\
\hline NYHA functional class, mean (range) & $3.2(2-4)$ & $1.5(1-3)$ & $<.001$ \\
\hline $\mathrm{I}, \mathrm{n}(\%)$ & 0 & $25(40.3)$ & \\
\hline II, $\mathrm{n}(\%)$ & $21(30.9)$ & $35(56.4)$ & \\
\hline III, n $(\%)$ & $23(33.8)$ & $2(3.2)$ & \\
\hline IV, n $(\%)$ & $24(35.2)$ & 0 & \\
\hline $\mathrm{VO}_{2 \max }, \mathrm{mL} / \mathrm{kg} / \mathrm{min}$, mean (range) & $15(10-40)$ & $24(18-48)$ & $<.02$ \\
\hline Oxygen saturation, $\%$, mean (range) & $92.0 \pm 5.0(76-97)$ & $98.2 \pm 0.7(95-100)$ & $<.001$ \\
\hline Severity of TV incompetence, mean (range) & $3.4(2-4)$ & $1.4(1-3)$ & $<.001$ \\
\hline None, n $(\%)$ & 0 & $18(29.03)$ & \\
\hline $\mathrm{I}, \mathrm{n}(\%)$ & 0 & $25(40.32)$ & \\
\hline II, n $(\%)$ & $11(16.1)$ & $16(25.8)$ & \\
\hline III, n (\%) & $26(38.2)$ & $3(4.8)$ & \\
\hline $\mathrm{IV}, \mathrm{n}(\%)$ & $31(45.6)$ & 0 & \\
\hline \multicolumn{4}{|l|}{ Ventricular function } \\
\hline Strain, \% mean & & & \\
\hline Basal & 18.08 & 25.7 & $<.011$ \\
\hline Middle & 15.6 & 23.7 & $<.001$ \\
\hline Apical & 13.9 & 19.36 & $<.05$ \\
\hline Velocity time integral, $\mathrm{cm} / \mathrm{s}$, mean (range) & & & \\
\hline $\mathrm{RV}$ (normal, $20.0 \pm 4.0$ ) & $16.7 \pm 6(10-24)$ & $20.0 \pm 4.0(13-37)$ & .05 \\
\hline $\mathrm{LV}($ normal, $22.0 \pm 4.0)$ & $18.2 \pm 3(11-25)$ & $23.0 \pm 3.0(10-38)$ & .03 \\
\hline
\end{tabular}

NYHA, New York Heart Association; $V O_{2 \max }$, maximal oxygen consumption; $T V$, tricuspid valve; $R V$, right ventricle/ventricular; $L V$, left ventricle/ventricular.

\section{Surgical Technique}

TV repair was performed through a median sternotomy under cardiopulmonary bypass. Myocardial protection was provided mostly with blood cardioplegia under normothermia or antegrade intermittent cold crystalloid cardioplegia with topical hypothermia. The situs was examined through a right atriotomy via an angulated oblique incision. As is typical for this complex anomaly, the pathological anatomy and morphology varied widely among the patients, and no 2 cases were alike in every respect; however, the characteristic features of Ebstein's anomaly were present in all patients, and thus the anatomy was classified according to type to guide the surgical techniques to be used. The atrialized ventricle, TV, and subvalvar apparatus were inspected to determine the precise morphology, assess leaflet coaptation, and determine which leaflet was the most mobile. The anatomic annulus of the TV was found to be enormously dilated in all cases, and the septal leaflet was displaced from its origin toward the RV cavity. The anterior and posterior leaflets were highly variable. The annular attachment of the posterior leaflet was displaced, thus giving rise to the formation of an atrialized chamber of various extent. This atrialized chamber occupied a moderate portion of the RV, depending on the Carpentier classification. ${ }^{12}$ The anterior leaflet was largest in all cases, and showed clefts or deep 
fenestrations in several cases. Various repair strategies ${ }^{16,23-25}$ were used according to the presenting morphology. No patient underwent TV replacement during the primary surgery. In all, the atrialized RV was incorporated into the contractile RV by partial closure of the natural annulus using the most mobile leaflet for valve competence.

Posterior annulorrhaphy, performed by passing a row of sutures along the posterior annulus, resulting in obliteration of the posterior half of the anatomic orifice, was performed for types $\mathrm{A}, \mathrm{B}$, and $\mathrm{C}$, with transection of fibrous bands of the anterior leaflet and ventricular wall (Figure 1, $A-D$ ), adding the atrialized chamber to the RV.

Sebening stitch, performed by placing a mattress suture from the anterior ventricular wall to the IVS (Figure 1,E) was applied in combination with posterior annulorrhaphy in all types. In patients with type A or B, the suture was passed through the head of the papillary muscle. In patients with type $\mathrm{C}$ or $\mathrm{D}$, a mattress suture was placed on the middle portion of the free anterior wall below the anterior leaflet and fibrous remnants were approximated to the opposite septal leaflet, to determine which portion of the anterior leaflet could be used for repair. After transvalvular saline instillation to test for leaflet coaptation and to assess the definite point for suture placement, a Sebening stitch was placed and tied down.

The double-orifice valve technique, ${ }^{26}$ used mostly in type $\mathrm{D}$, was accomplished by passing sutures from the middle of the true anterior annulus to the opposite true annulus above the septal leaflet (Figure 1, F and $G$ ). Traction on the anterior leaflet was applied with a nerve hook to facilitate identification of the true tricuspid annulus and to suture placement. The annular apposition divides the TV into 2 orifices, enabling valve competence on both (Figure $1, H$ and $I$ ).

A combination of anterior and posterior annulorrhaphy was also performed for types $\mathrm{A}$ and $\mathrm{B}$.

An additional bidirectional Glenn anastomosis was performed at the end of the repair in 3 patients with type $\mathrm{C}$ with decreased RV contractility. In these 3 patients, the mean pulmonary artery pressure was $12.8 \pm 1.3 \mathrm{~mm}$ $\mathrm{Hg}$ (range, $10-18 \mathrm{~mm} \mathrm{Hg}$ ) and mean left atrial pressure was $7.1 \pm 2.6 \mathrm{~mm} \mathrm{Hg}$ (range, $5-12 \mathrm{~mm} \mathrm{Hg}$ ). The decision to perform a bidirectional Glenn anastomosis was considered when the hemodynamic and echocardiographic assessment showed that the total cardiac output could not be maintained by the RV, and was not based on the Carpentier classification. This procedure was discussed preoperatively in a 15 -year-old patient with advanced heart failure. In another patient, the decision was made intraoperatively, when the postrepair hemodynamic parameters showed that the RV would not be able to sustain the cardiac output. The third case was a 5-year-old child who was repeatedly resuscitated and had a biventricular assist device for 17 days until myocardial recovery. When she finally underwent repair of Ebstein's anomaly, performing a Glenn anastomosis was a straightforward decision.

All associated anomalies, such as atrial and ventricular septal defects, pulmonary stenosis, and mitral valve insufficiency, were corrected concomitantly. Intraoperative transesophageal echocardiography was routinely performed to assess the adequacy of repair. No patient was discharged from the hospital with more than mild degree of insufficiency.

\section{Follow-up}

Patient follow-up records were provided by the Department of Congenital Heart Disease/Pediatric Cardiology and Department of Clinical Studies, Deutsches Herzzentrum Berlin, and by written correspondence from the referring physicians. No patients were lost to follow-up, and thus the records are $100 \%$ complete. Postoperative transthoracic Doppler echocardiography was performed at 3,6, and 12 months postoperatively, then twice in the second year and annually thereafter, or at any time during the follow-up as clinically indicated based on symptoms. The degree of tricuspid insufficiency was estimated by standard echocardiographic measurement techniques. Ventricular function was assessed using Doppler echocardiography until 2000, and since that time displacement TDI has been used to evaluate overall performance of the RV, LV, and IVS.

\section{Statistical Analysis}

All data were analyzed with SPSS for Windows version 22.0 (IBM, Armonk, NY). Data are expressed as absolute and percentage frequency values, and continuous data are expressed as mean $\pm \mathrm{SD}$ and/or median and range, as appropriate. Variables such as New York Heart Association (NYHA) functional class, severity of TV insufficiency, exercise tolerance (oxygen saturation at rest) and ventricular contractility (basal, middle, and apical ventricular strain of both the LV and RV) were analyzed using a paired $t$ test. Differences in preoperative and postoperative/follow-up values were analyzed using the Wilcoxon test. A $P$ value $\leq .05$ was considered significant. Freedom from reoperation and cumulative survival rates were analyzed according to Kaplan-Meier estimates with 95\% confidence intervals.

\section{RESULTS \\ Morbidity}

Three patients $(4.4 \%)$, including 1 patient with preoperative Wolff-Parkinson-White syndrome, 1 with preoperative sick sinus syndrome, and 1 with complete atrioventricular block, required permanent pacemaker implantation performed within 30 days after the operation.

\section{Survival}

Early mortality. Two patients $(2.9 \%)$ died of multiorgan failure. One of these patients (age 52 years, type C) had septic endocarditis and mediastinitis, and the other (age 48 years, type D) developed acute renal failure, pneumonia, and sepsis.

Late mortality. A total of 4 deaths $(5.8 \%)$ ) occurred during the postoperative follow-up period. All of these patients were in the older age group (range, 52-55 years), 1 with type B, 2 with type C, and 1 with type D. All were in NYHA functional class III or IV. Three patients died from multiorgan failure (at 3, 4, and 10 years postoperatively), and the other died from myocardial infarction (at 7 years postoperatively).

The mean duration of follow-up was $13.25 \pm 1.3$ years (median, 9.34 years; range, 1-24 years). All of the 62 surviving patients have had a follow-up of $>1$ year. The overall survival rate was $97.6 \% \pm 2.4 \%$ at 30 days and $91.2 \% \pm 4.3 \%$ at 20 years (Figure $2, A$ ).

\section{Freedom From Reoperation}

A 7-year-old patient with type C Ebstein's anomaly underwent TV replacement with a biological valve at 7 months postoperatively and eventually underwent another mechanical valve replacement 5 months later. Three other patients underwent reoperation: a 9-year-old with type A Ebstein's anomaly for pulmonary valve replacement 5 years postoperatively and 2 others for a pacemaker change, at 3 and 6 years after the initial pacemaker implantation. Freedom from reoperation was $100 \%$ at 30 days, $98.3 \%$ at 5 years, and $92.9 \%$ at 20 years (Figure 2, B). 

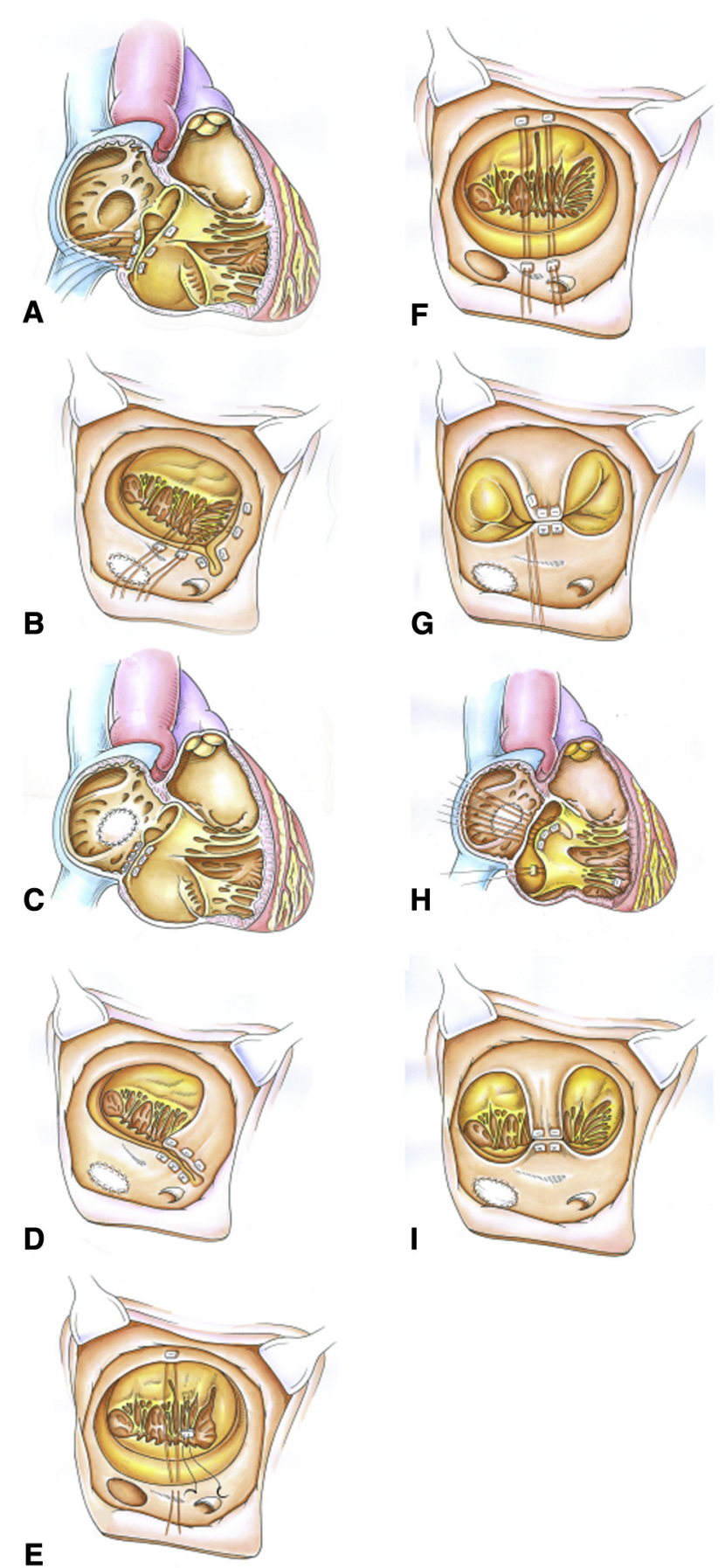

FIGURE 1. Repair techniques. A, Posterior annulorrhapy: a row of sutures placed from the anterior annulus to the true annulus above the atrialized chamber, resulting in obliteration of the posterior half of the anatomic orifice (lateral view), adding the atrialized chamber to the RV. $\mathrm{B}$, Atrial view showing the row of sutures along the true annulus. C, Under ventricular filling, the anterior leaflet closes the new ostium. D, Atrial view showing a competent TV. E, Sebening stitch is performed by placing a mattress suture from the anterior ventricular wall to the IVS, bringing together the tips of the anterior papillary muscles and fibrous remnants of the opposite septal leaflet. F, Double-orifice valve technique: sutures placed from the middle of the true anterior annulus to the opposite true

\section{Functional Outcome of TV Repair}

Change in functional class. There was a significant improvement in functional class, from a preoperative mean functional class of 3.4 (range, 2-4) to a postoperative (3 months, 1 year, and latest individual follow-up) mean functional class of 1.4 (range, 1-3) $(P<.001)$, and this improvement was sustained until the late follow-up period (Table 1 and Figure 3, A) for each patient.

Change in severity of tricuspid insufficiency. There was a significant improvement in the severity of tricuspid insufficiency after the TV repair, from a preoperative mean tricuspid insufficiency grade of 3.2 (range, 2-4) to a postoperative (3 months, 1 year, and latest individual follow-up) mean tricuspid insufficiency grade of 1.13 (range, 1-3) $(P<.001)$ (Figure 3, $B)$.

Exercise tolerance. Within the 26-year period, a total of 2964 exercise tolerance tests were performed in 38 patients. The mean preoperative $\mathrm{VO}_{2 \max }$ value was $15 \pm 7.8 \mathrm{~mL} / \mathrm{kg} / \mathrm{min}$ (range, $10-40 \mathrm{~mL} / \mathrm{kg} / \mathrm{min}$ ), and the mean follow-up $\mathrm{VO}_{2 \max }$ value was $24.9 \pm 2.0 \mathrm{~mL} / \mathrm{kg} / \mathrm{min}$ (range, $18-48 \mathrm{~mL} / \mathrm{kg} / \mathrm{min})(P<.02)$ (Figure $3, C$ ).

The mean oxygen saturation rate improved from $92.0 \% \pm 5.0 \%$ (range, $76 \%-97 \%$ ) preoperatively to $98.2 \% \pm 0.7 \%$ (range, $95 \%-100 \%$ ) postoperatively and during follow-up $(P<.001)$ (Figure 3,D).

Ventricular function tests. Displacement TDI showed an improvement in mean basal, middle, and apical ventricular strain from preoperative values of $18.08 \%, 15.6 \%$, and $13.9 \%$, respectively, to postoperative values of $25.7 \%$ $(P<.011), 23.7 \%(P<.001)$, and $19.36 \%(P<.05)$, respectively.

RV contractility (measured by pulmonary flow velocity time integral) improved from a preoperative mean of $16.0 \pm 3.0 \mathrm{~cm} / \mathrm{s}$ to a postoperative mean of $20.0 \pm 4.0 \mathrm{~cm} / \mathrm{s}(P=.05)$ (normal, $20.0 \pm 4.0 \mathrm{~cm} / \mathrm{s}$ ) (Figure 4, A). Likewise, LV contractility (measured by aortic flow velocity time integral) improved from a preoperative mean of $17.0 \pm 4.0 \mathrm{~cm} / \mathrm{s}$ to a postoperative mean of $23.0 \pm 3.0 \mathrm{~cm} / \mathrm{s}(P=.03)$ (normal, $22.0 \pm 4.0 \mathrm{~cm} / \mathrm{s}$ ) (Figure 4, B).

Serial echocardiography of surviving patients revealed no thrombosis or aneurysm formation on the unplicated atrialized chamber, and no recurrent annular dilatation.

\section{DISCUSSION}

Anatomic variations of Ebstein's anomaly have posed a significant surgical challenge since the earliest repair techniques were developed. Undoubtedly, valve repair

annulus above the septal leaflet. G, Atrial view showing several sutures placed to create a double-orifice valve. $\mathrm{H}$, Lateral view of the doubleorifice valve technique showing a row of annular sutures and the Sebening stitch below. I, Atrial view of completed double-orifice valve technique. 


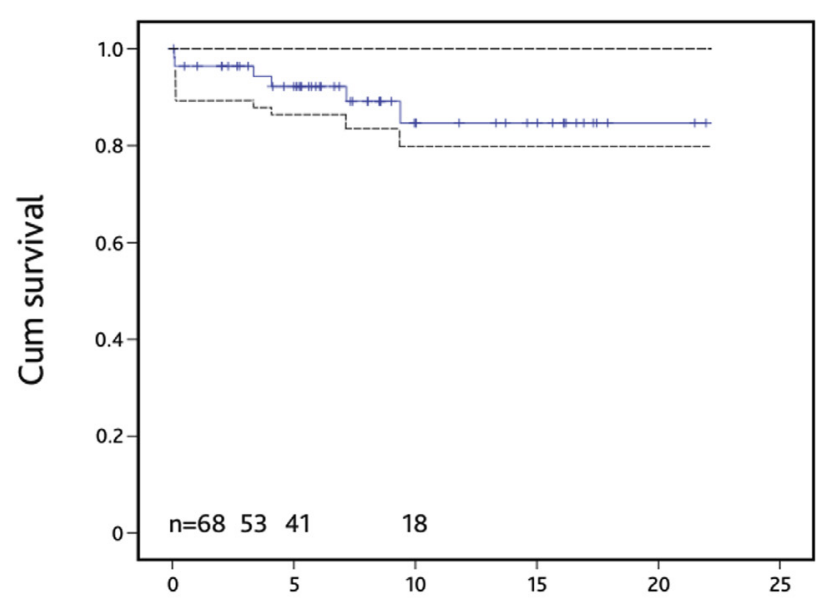

A

Time (postoperative, years)

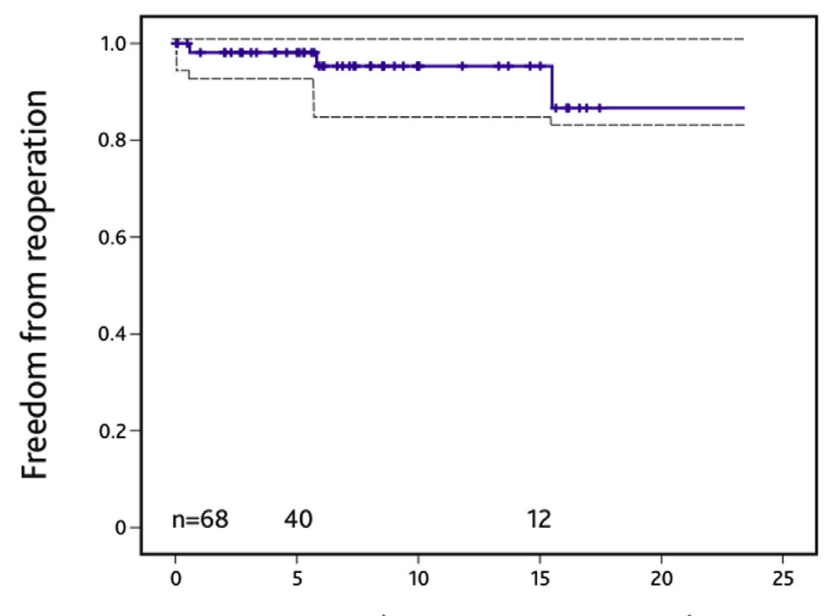

B

Time (postoperative, years)

FIGURE 2. Kaplan-Meier curves at $95 \%$ confidence interval showing (A) cumulative survival and (B) freedom from reoperation.

produces favorable long-term results and abates the natural history of the disease. Most repair techniques address the abnormal TV with the concept of monocusp repair. Danielson and colleagues ${ }^{10}$ described a corrective technique using transverse plication of an atrialized portion of the RV and right atrial reduction. Later, Carpentier and colleagues ${ }^{5}$ modified the technique by taking reconstructed TV leaflets to the true tricuspid annular level using a prosthetic ring to reinforce the reconstructed annulus, and also excluded the atrialized chamber by longitudinal plication. Quaegebeur and colleagues ${ }^{13}$ and Chauvaud and colleagues ${ }^{15}$ performed longitudinal plication to restore the geometry and compliance of the RV, in addition to valvuloplasty. In the technique applied by $\mathrm{Wu}$ and colleagues, ${ }^{18}$ the TV was first returned to a normal anatomic level, after which a partial resection of the atrialized portion of the RV was completed, and a new septal leaflet was constructed using fresh autologous pericardium. In another recent series, da Silva and colleagues $^{19}$ described a cone reconstruction technique that uses the Carpentier ${ }^{12}$ concept, restoring the TV to the true annulus and performing a longitudinal plication of the atrialized RV; the TV and the subvalvar apparatus were reconstructed like a cone, which permitted a central diastolic blood flow correction. Each of these techniques has provided good mid-term results; however, although the cone technique could be applicable to almost all anatomic subtypes, concerns have been raised about its application in Ebstein's anomaly type D, where there is complete absence of leaflets and only fibrous remnants are attached to the RV wall.

Likewise, none of these reported techniques addresses the spectrum of patients with each morphological type of Ebstein's anomaly. The Carpentier ${ }^{12}$ anatomic classification is the sole classification scheme that addresses the severity of anatomic abnormalities and is based on the relationship of the atrialized chamber to the true ventricle. Although the pathological morphology of Ebstein's anomaly is highly variable, this classification scheme is valuable in deciding the repair strategy to be followed.

We believe that the tricuspid annulus must not be shortened to the same degree for all patients, and that anatomic correction is not possible at all times. With these considerations in mind, the technical concept that we have developed is restoration of TV functional competence, individualized according to the presenting Ebstein morphology, and without plication of the atrialized chamber. Clearly, a single technique might not be able to restore TV competence in each type. This Ebstein type-based repertoire of repair techniques allows adequate repair even in severe types in which only a remnant of the anterior or posterior leaflet may be available for valve remodeling.

In our series, we encountered all types of Ebstein's anomaly, and modified our repair techniques accordingly, ${ }^{17,24}$ even in cases of variations of each type. In extreme cases of type $\mathrm{D}$, we found that the double-orifice valve technique was the most appropriate approach for restoring valve competence. Based on the satisfactory outcome in this group, we have preferred this technique since 2002 in almost all types of Ebstein's anomaly. We add the Sebening stitch to support the repair and help alleviate suture tension when approximating the anterior annulus to the septal annulus. We have learned that repair by passing pledgeted mattress sutures from the middle of the true anterior annulus to a spot on the opposite septal annulus, located at approximately two-thirds of the length of the septal annulus, avoids injury to the bundle of His and, with this increasing experience, we did not encounter any rhythm complications except in 3 patients in our early years.

Issues regarding the importance of the atrialized chamber have been raised, and most repair techniques include either transverse plication or longitudinal plication of this area. 

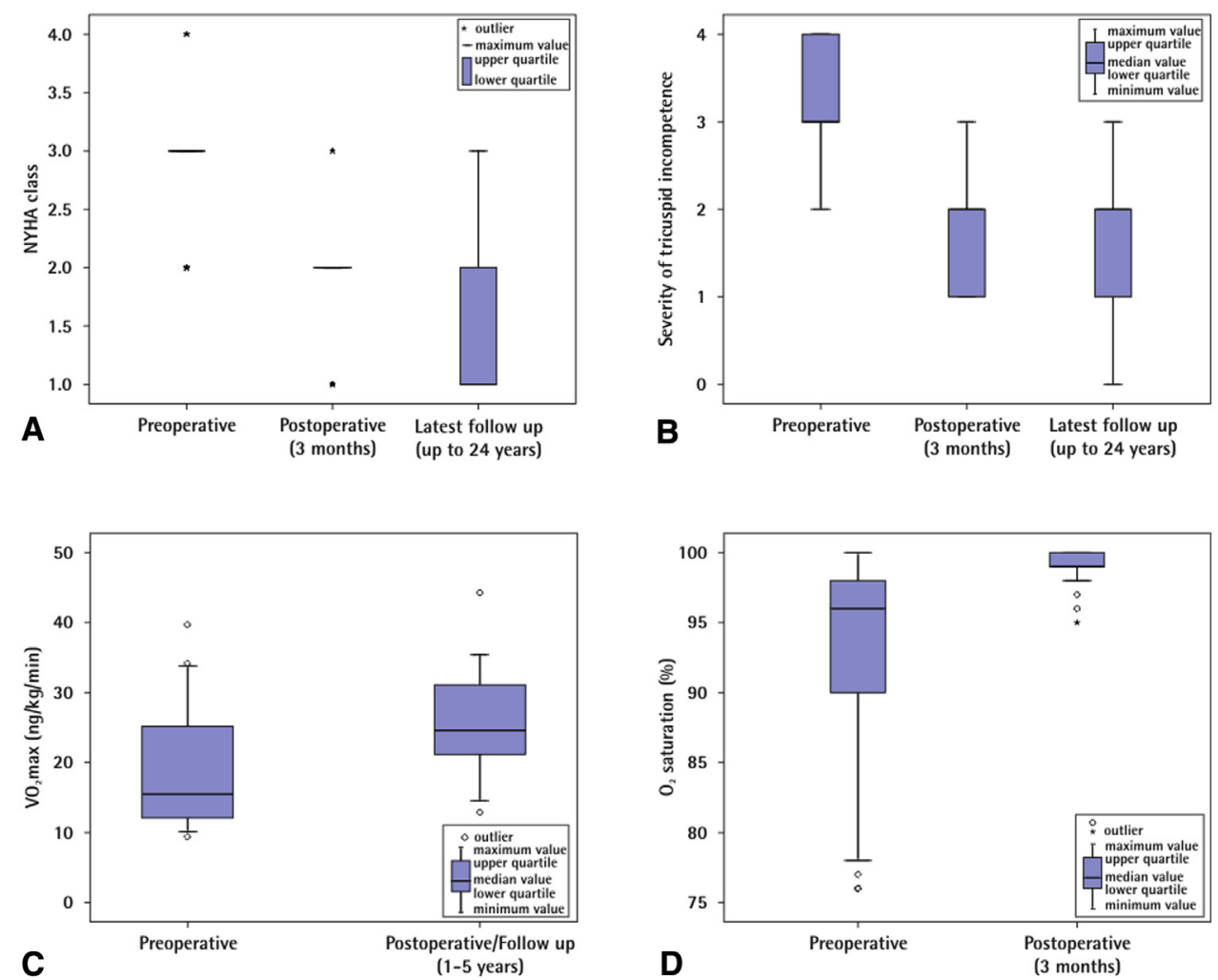

FIGURE 3. Functional outcomes. A, Change in NYHA functional class. B, Change in severity of tricuspid regurgitation. C, Exercise tolerance tests. D, Oxygen saturation. $N Y H A$, New York Heart Association; $\mathrm{VO}_{2 \max }$, maximal oxygen consumption; $\mathrm{O}_{2}$, oxygen.

Concerns have been expressed that this chamber, when exposed to the RV pressure, might have a similarly negative effect on ventricular energy economics, as does an LV aneurysm on the LV. ${ }^{13}$ It also has been postulated that stasis within this noncontractile sac might promote thrombosis. It was then assumed that, with longitudinal plication, RV function may be enhanced and the characteristic rhythm disturbances may be abated. ${ }^{12}$ However, we argue that in TV replacement for Ebstein's anomaly, the atrialized chamber is left as it is, which has no negative consequences. Schmidt-Habelmann and colleagues ${ }^{11}$ reported a technique with excellent long-term results in which the base of the anterior leaflet chordal attachment is fixed with a single suture placed on a muscular portion of the atrialized septum, now called the Sebening stitch (named after the senior author), without inclusion of the atrialized chamber itself.

In our case series of 68 patients with Ebstein's anomaly, we made no attempt to reduce or obliterate this chamber. To date, we have not seen any further enlargement of the RV or any occurrence of thrombosis of aneurysm of this area. We assume that its incorporation into the contractile RV may even be beneficial, in allowing sufficient RV diastolic filling, and could stimulate the remaining musculature in the atrialized chamber wall toward hypertrophy, thus contributing to RV contraction. This is presently the subject of an ongoing study at our institution. We do not hesitate to perform a concomitant Glenn anastomosis whenever necessary, to help unload the RV and improve cardiac output in the presence of decreased RV function.

Reduction of the tricuspid orifice at the level of the true annulus by posterior annulorrhaphy has not led to stenosis, as evidenced by the normal inflow velocity seen on echocardiography. Annuloplasty was not performed or deemed necessary in any case, given the satisfactory results obtained with posterior annulorrhaphy and the double-orifice valve technique.

The postoperative improvement in NYHA functional class was apparent in long-term follow-up, proportional to the increase in $\mathrm{VO}_{2 \max }$. In addition, TV competence was restored and sustained during the course of follow-up. The postoperative increase in pulmonary and aortic flow velocity time integrals strongly suggests that these techniques without plication of the atrialized chamber improve ventricular function postoperatively and over time.

This repertoire of techniques used has provided good long-term results. Since 2004, no early or late mortality occurred, even in the patients age $>50$ years and in NYHA functional class III and IV during the primary procedure. 

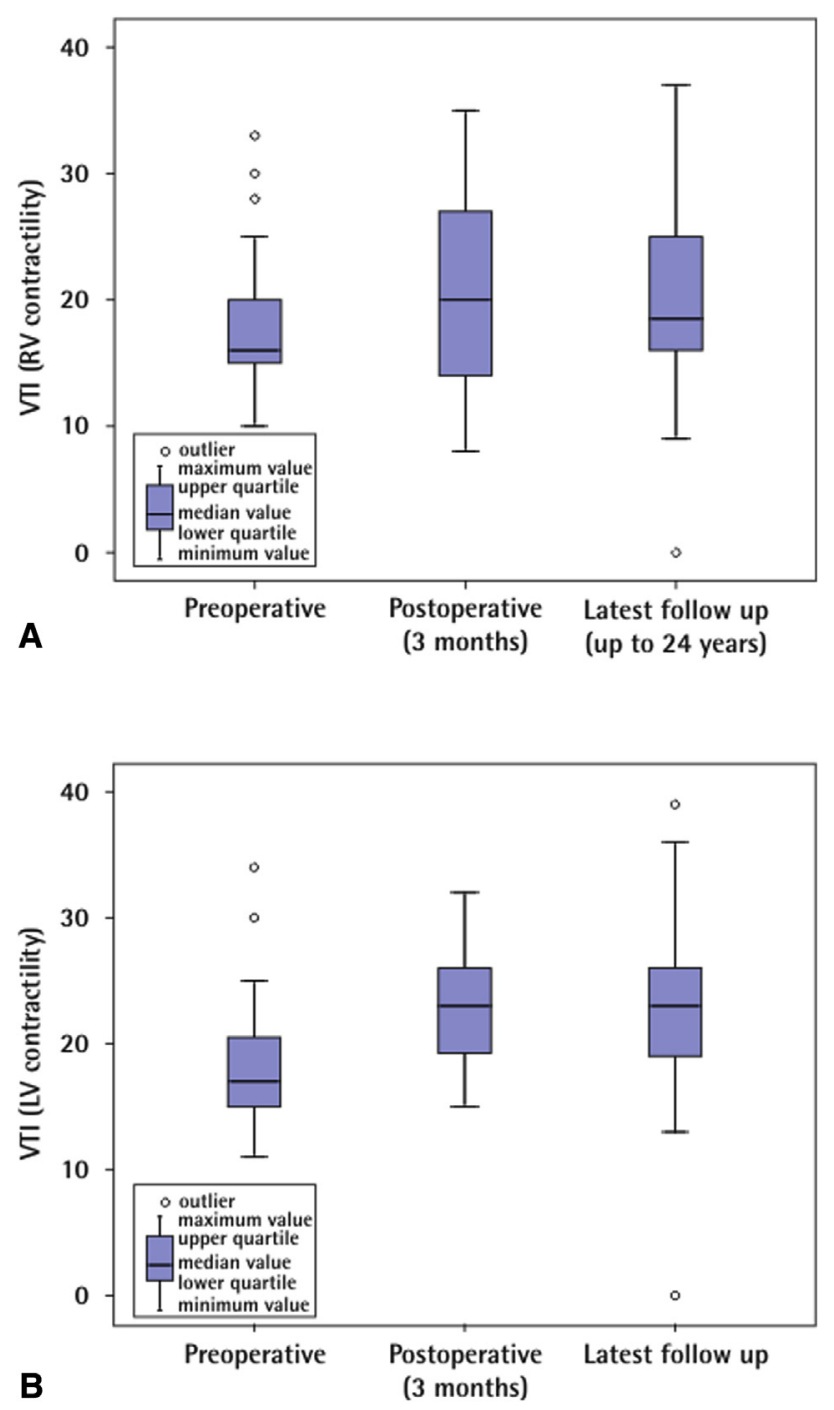

FIGURE 4. Ventricular function tests by TDI. A, RV contractility, measured by pulmonary flow velocity time integral. B, LV contractility, measured by aortic flow velocity time integral. $V T I$, velocity time integral; $R V$, right ventricle/ventricular; $L V$, left ventricle/ventricular.

\section{CONCLUSION}

Based on our experience, all types of Ebstein's anomaly are amenable to repair. The various repair techniques, which preserve the atrialized chamber and are used according to morphology, provide satisfactory long-term ventricular function and functional outcome even in severe types of Ebstein's anomaly.

\section{Conflict of Interest Statement}

Authors have nothing to disclose with regard to commercial support.

We thank Anne Gale, medical editor, for assistance with this article. We appreciate the help of Astrid Benhennour for literature searches, Julia Stein for statistical analysis, and Carla Weber and Helge Haselbach for graphics.

\section{References}

1. Ebstein W. On a very rare case of insufficiency of the tricuspid valve caused by a congenital severe deformity. Arch Anat Physiol Wiss Med. 1866;7:238-54 (in German).

2. Kouchoukos NT, Blackstone EH, Doty DB, Hanley FL, Karp RB. Ebstein anomaly. In: Kirklin JW, Barratt-Boyes BG, eds. Cardiac Surgery. 3rd ed. New York: Churchill Livingston; 2003:1177-99.

3. Lee CM, Sheehan FH, Bouzas B, Chen SS, Gatzoulis MA, Kilner PJ. The shape and function of the right ventricle in Ebstein's anomaly. Int J Cardiol. 2013;167:704-10.

4. Brown ML, Dearani JA, Danielson GK, Cetta F, Connolly HM, Warnes CA, et al. Effect of operation for Ebstein anomaly on left ventricular function. Am J Cardiol. 2008;102:1724-7.

5. Lang D, Oberhoffer R, Cook A, Sharland G, Allan L, Fagg N, et al. Pathologic spectrum of malformations of the tricuspid valve in prenatal and neonatal life. $J$ Am Coll Cardiol. 1991;17:1161-7.

6. Dearani JA, Danielson GK. Congenital Heart Surgery Nomenclature and Database Project: Ebstein's anomaly and tricuspid valve disease. Ann Thorac Surg. 2000;69(4 Suppl):S106-17.

7. Kumar AE, Fyler DC, Miettinen OS, Nadas AS. Ebstein's anomaly: clinical profile and natural history. Am J Cardiol. 1971;28:84-95.

8. Hardy KL, May IA, Webster CA, Kimball KG. Ebstein's anomaly: a functional concept and successful definitive repair. J Thorac Cardiovasc Surg. 1964;48:927-40.

9. Lillihei CW, Kalke BR, Carlson RG. Evolution of corrective surgery for Ebstein's anomaly. Circulation. 1967;35:1111-8.

10. Danielson GK, Maloney JD, Devloo RA. Surgical repair of Ebstein's anomaly. Mayo Clin Proc. 1979;54:185-92.

11. Schmidt-Habelmann P, Meisner H, Struck E, Sebening F. Results of valvuloplasty for Ebstein's anomaly. Thorac Cardiovasc Surg. 1981;29:155-7.

12. Carpentier A, Chauvaud S, Macé L, Relland J, Mihaileanu S, Marino JP, et al. A new reconstructive operation for Ebstein's anomaly of the tricuspid valve. $J$ Thorac Cardiovasc Surg. 1988:96:92-101.

13. Quaegebeur JM, Sreeram N, Fraser AG, Bogers AJ, Stümper OF, Hess J, et al. Surgery for Ebsteins's anomaly: the clinical and echocardiographic evaluation of a new technique. J Am Coll Cardiol. 1991;17:722-8.

14. Starnes VA, Pitlick PT, Bernstein D, Griffin ML, Choy M, Shumway NE Ebstein's anomaly appearing in the neonate: a new surgical approach. $J$ Thorac Cardiovasc Surg. 1991;101:1082-7.

15. Chauvaud SM, Mihaileanu SA, Gaer J, Carpentier AC. Surgical treatment of Ebstein's malformation: the Hôpital Broussais experience. Cardiol Young. 1996;6:4-11.

16. Hetzer R, Nagdyman N, Ewert P, Weng YG, Alexi-Meskhisvili V, Berger F, et al. A modified repair technique for tricuspid incompetence in Ebstein's anomaly. $J$ Thorac Cardiovasc Surg. 1998;115:857-68.

17. Kreutzer C, Mayorquim RC, Kreutzer GO, Conejeros W, Roman MI, Vasquez H, et al. Experience with one and a half ventricle repair. J Thorac Cardiovasc Surg. 1999;117:662-8.

18. Wu Q, Huang Z. Anatomic correction of Ebstein anomaly. J Thorac Cardiovasc Surg. 2001;122:1237-8.

19. da Silva JP, Baumgratz FJ, Fonseca L, Franchi SM, Lopes LM, Tavares GM, et al The cone reconstruction of the tricuspid valve in Ebstein's anomaly. The operation: early and midterm results. J Thorac Cardiovasc Surg. 2007;133:215-23.

20. Jones NL. Clinical Exercise Testing. 3rd ed. Philadelphia: Saunders; 1988.

21. Weidemann F, Eyskens B, Sutherland GR. New ultrasound methods to quantify regional myocardial function in children with heart disease. Pediatr Cardiol. 2002;23:292-306.

22. Tei C, Ling LH, Hodge DO, Bailey KR, Oh JK, Rodeheffer RJ, et al. New index of combined systolic and diastolic myocardial performance: a simple and reproducible measure of cardiac function. A study in normals and dilated cardiomyopathy. J Cardiol. 1995;26:357-66.

23. Komoda T, Komoda S, Nagdyman N, Berger F, Hetzer R. Combination of a Hetzer operation and a Sebening stitch for Ebstein's anomaly. Gen Thorac Cardiovasc Surg. 2007;55:355-9.

24. Nagdyman N, Ewert P, Komoda T, Alexi-Meskisvili V, Weng Y, Berger F, et al. Modified repair in patients with Ebstein's anomaly. J Heart Valve Dis. 2010;19:364-9.

25. Hetzer R, Komoda T, Delmo Walter EM. How to do the double-orifice valve technique to treat tricuspid valve incompetence. Eur J Cardiothorac Surg. 2013;43:641-2.

26. da Silva JP, da Silva Lda F. Ebstein's anomaly of the tricuspid valve: the cone repair. Semin Thorac Cardiovasc Surg Pediatr Card Surg Annu. 2012;15:38-45.

Key Words: Ebstein's anomaly, tricuspid valve, ventricular function, atrialized chamber 